dropped nearest a convergence. If the convection cells were symmetrical, the leading bottle in each line should be followed by equal numbers from the left and the right; in all but three of his eighteen experiments, bowever, there were more from the left, and the average was 60 per cent. He concludes that the right-hand convection cell is most strongly developad.

Attempts have been made to use the effect of the earth's rotation to explain the symmetrical develop. ment of the convection colls, but without success. Munk has suggested that the convection cells are combined with a drift of the Ekman type.

Mr. F. Ursell then outlined an investigation of waves as they are affected by the rotation of the earth. It was shown by Stokes that regular trains of water waves are accompanied by a mass transport in the direction of propagation, provided that the effects of non-conservative forces such as the viscous forces and the Coriolis force are negligible so that the waves are free from vorticity. It has been suggested that this transport might set up largescale ocean currents. However, in geophysical applications, the Coriolis force may not be negligible and vorticity may be generated. This question requires mathematical study. An idealized problem has been considered by Mr. Ursell in which the geopotential gradient (including the centrifugal force) is constant in magnitude and direction; so the wave motion may be thought of as taking place on a plane earth, on which there is a Coriolis field. In the first place, considering regular wave trains which can travel unchanged in such a field, it is necessary to take the non-linear equations of motion, as the mass transport is considerable only for waves of substantial height. But for non-linear equations the principle of superposition does not apply, so that we cannot hope for a complete solution of the equations. (An illustration was given of the difference between linear and nonlinear behaviour.) Nevertheless, a good deal can be said about the mass transport. Mr. Ursell began by showing that the plane touching all the crests is normal to the direction of gravity. Then, by an extension of Bernoulli's theorem, it was shown that the mass transport, if any, must be in the direction of propagation. Finally, Bjerknes's theorem on the circulation along a circuit moving with the fluid was used to show that the mass transport at any depth is zero, so that the fluid particles move in closed orbits. The stationary state of waves on a rotating earth must therefore approximate closely to the type studied by Gerstner (1802) rather than to Stokes waves. The foregoing arguments do not apply on the equator.

Bjerknes's theorem may also be applied to the nonstationary state. Consider an area of still water which is being invaded by waves. The motion is initially irrotational, so that the waves formed in this area are initially of Stokes type. As they build up, a mass transport is set up. Bjerknes's theorem then shows that this current changes its direction continuously, the direction turning through four right angles in 12 cosece hours, where $\varphi$ is the latitude. Ocean waves should therefore be accompanied by rotating inertia currents. Such currents have hitherto been explained as set up by a wind drag on the surface which ceases when a current has been established. This requires a large value of the eddy viscosity, which would lead to very rapid damping of the resulting motion. It may be that the wave mechanism described here will serve to explain some known inertia currents satisfactorily, but further measurements of waves are needed before a detailed comparison can be made.

Lastly, Mr. R. H. Corkan gave an account of the derivation of certain constants of the sea, of interest to oceanographers, a by-product of his work on storm surges. These surges are waves of much longer periods than surface waves, and the associated transport of water is of great importance. It might be thought that a single woll-developed surge would give information as to the period of the oscillation, and that its rate of decay would give an approximate value of the coefficient of eddy viscosity. It was stated that such a simple method cannot ba used for surges experienced in the Thames, since the surge has three main contributions: one from local winds, one from winds over the North Sea, and one from a surge propagated inwards from the north of Seotland and travelling around the North Sea in an anticlockwise direction. The latter contribution is a passing wave, and its rate of decay cannot be ascer. tained from observations at a single place, such as are applicable in studying the decay of on oscillation of the see itself. The removal of such an external effect and the allowance for periodic variations in the winds are necessary before the data can be utilized for the desired constants.

Mathematical formulæ for the oscillation of the sea under the influence of a variable wind were $d$ sscribed. These involva the free period of the sea and the eddy viscosity. After the wind dies down, there is a decaying oscillation with the free period, which was quite accurately determined from a large number of surges as $30 \mathrm{hr}$., and the ratio of the first positive amplitude to the next negative amplitude was shown to be approximately 4 , so that the decay is very rapid. Very precise figures could not be given because of the complexity of the phenomenon, but it was shown that the mathematical formulæ were justified only on the assumption of no bottom current; the alternative of finite bottom current would require unduly large current velocitios. The decay factor corrosponds to a coefficient of eddy viscosity of about 1,300 o.G.s. units.

The relation between wind velocity and elevation, with the damping factor of 4 , with certain assumptions as to the effective length of channel over which it operated, gave a stress coefficient of 0.0023 c.c s. units. This is in good agreement with values obtained by other investigators, and showed that the various results derived from the investigation were in conformity with one anotber. The need for caution in deducing constants from observations uncorrected for all possible oscillatory causes was fully evident.

There was unfortunately very little opportunity for discussion.



\section{THE KAURI TREE IN NEW ZEALAND}

$\Delta \mathrm{N}$ article deqling of the controversy over the question of fopreservation of the famous kauri tree of New/Zealind, with particular reference to the treatmen fafd control of Waipoua Forest, was publisfec in Nature of January 10, 1948. The article epcid on an optimistic note, as it was felt that it should not be difficult to reach agreement. Unfortunately, that agreement has not been reached, 


\section{No. 4137 February 12, $1949 \quad$ N A T U R E}

mainly as one side feels unable to accept any compromise and appears convinced that nothing short of constituting the whole 40,000 acres a national park of the type in which nothing may ever be touched would meet requirements.

The latest development is the private publication by Mr. W. R. McGregor of an attractive booklet on the Waipoua Kauri Forest*. In producing this account, Mr. McGregor has done a real service to the wide public in New Zealand and the world over that is interested in the preservation of the best examples of natural vegetation still available for the enjoyment and study of future generations. He has a ready pen, and his descriptions reveal a deep love of the wild forest and an almost fanatic desire to exclude any activity in or near it that may threaten its wildness and solitude. The book is, moreover, profusely and excellently illustrated with fifty-six photographs. No attempt is made to disguise the fact that the author regards the State Forest Service as 'Enemy No. 1'. Indeed, perusal of the book leaves one with the impression that the object of its pub. lication is to try to win popular support for bringing pressure to bear on the Government to withdraw the forest completely from control by the Forest Service and to constitute the whole of it a national park under some other authority on the lines adopted in Canada and the United States. This attitude leads to various charges against the Forest Service which one is reluctant to accept literally, and which, indeed, would be indignantly rebutted by the professional forester the world over.

Like any other Government Department, the Forest Department is the servant of the State, responsible for carrying out the policy of its Government, and Mr. McGregor is clearly on firmer ground when he charges (p. 11) the New Zealand public with "complete failure to develop a forest policy adequate to the needs of this country". It is rightly pointed out that the will of the people should determine the use of public land, and the reasons are marshalled why this particular area should be reserved, not for commercial forestry but as a strict Nature reserve in which no human interference with the natural processes of growth, decay and replacement should be permitted.

The reader is also reminded that ever since the original reservation of Waipoua in 1885 there have been various clear indications that those in responsible positions have viewed the forest as such a reserve. Thus Massey declined to sanction the construction of the public road which now traverses the forest, and, even when in 1926 it was built, the then Prime Minister gave assurances that timber would not be cut, and that the object of the road was only to give access for the public to see the kauri.

We understand that even the much maligned Forest Service has agreed that selected areas of the best kauri-bearing forest; as well as a strip all along the highway and individual trees of outstanding interest, should be excluded from forest management; and the real issue seems to be that of the precise extent of the desired Nature reserve. Mr. MeGregor elaims that the whole forest (about 40,000 acres, 27,600 being under forest) must be constituted a complete Nature sanctuary to safeguard the kauri, and he will contemplate no compromise. He gives

* The Waipoua Forest: the Last Virgin Kauri Forest of New Zealand. By W. R. McGregor. Pp. 80. (Auckland, N.Z. : The Author, Department of Zoology, University College, 1949.) 58 . no grounds to substantiate this claim except in the vaguest terms, and intense distrust of the Forest Service seems his strongest argument. Some of these charges are patently biased, while the pen-picture of the managed forest (p. 78) reveals a surprising ignorance of modern forestry objectives and practices.

The constitution of large national parks by Canada and the United States is quoted as a precedent to be followed, and it is urged that New Zealand should constitute such a park to save for future generations the last virgin kauri forest of New Zealand. The former countries have, indeed, many millions of acres of national parks, much of them under forest, in which no fellings are allowed (except for insect. infested or fungus-attacked trees); but they also still have vast extents of productive forests, so that the position is entirely different. The Waipoua proposition, however, clearly needs careful examination, action being stayed in the meantime to leave all possibilities open. The thesis is readily acceptable that though the kauri itself is the outstanding species to be preserved, it is unlikely that this aim can be achieved without equally protecting the native vegetation types with which the kauri is associated, particularly as knowledge of their life-history is still extremely slight. Clearly the areas selected for the preservation of the existing giant kauri should be of such extent as to include adequate samples of the other natural forest communities, some of which may be found to alternate in time with those in which kauri is now present. It can also be accepted that the amount of timber which could be obtained from Waipoua is not of great importance, either as a contribution to the total supply or specifically as special-purpose timber.

It may well be decided that to guarantee the safety of the kauri and preserve the associated vegetation it is not necessary to withdraw 40,000 acres from timber production; but early and full examination of the whole matter by a fully representative com. mittee or commission is urgently needed. If, on the basis of its report, the country, through its elected representatives, decides in favour of the Nature reserve or national park project for a part or the whole of the forest, there should be no further hesitation in declaring that to be the decision, and so end the controversy. It may be instructive to note the action which has been taken by the State of California to preserve the redwoods along the comparatively new Redwood Highway, where relatively small blocks of forest, from a few to a few hundred acres, have been reserved or acquired in one way or another and constituted State parks. The species is adequately preserved in the surrounding forests which are under felling and regeneration by the State or private owners, the special steps being required only for the preservation of outstandingly fine trees or groves easy of access to the public.

There is also an interesting comparison to be made with the proposal now before the public in Great Britain that the State foresters should be empowered to take appropriate action to preserve and ensure the perpetuation of the oldest parts of the New Forest. These remnants are in real danger of disappearance because the requisite powers are at present lacking. In undertaking this task, the Forestry Commission would have no prospect of any financial return but only of additional expenditure.

H. G. CHAMPION 